\title{
Michael Freeden, Liberalismo. Una introducción
}

(2019) Página Indómita Madrid, 277pp.

\author{
Paloma de la Nuez Sánchez-Cascado \\ Universidad Rey Juan Carlos \\ ORCID ID 0000-0003-2714-4533 \\ paloma.delanuez@urjc.es
}

Cita recomendada:

Nuez Sánchez-Cascado, P. de la (2020). Michael Freeden, Liberalismo. Una introducción. Eunomía. Revista en Cultura de la Legalidad, 19, pp. 608-611.

doi: https://doi.org/10.20318/eunomia.2020.5732

Michael Freeden, profesor emérito de Oxford, es un autor reconocido internacionalmente (como demuestran sus varios premios y distinciones) por su obra en el campo de la Historia del pensamiento político, de las Ideologías (en especial el Liberalismo) y la Teoría política, intereses todos ellos relacionados entre sí.

De hecho, para los que estudian Ciencias Políticas y para los que la enseñan y se dedican a ella, las obras de M. Freeden son fundamentales si uno quiere comprender el mundo político en el que vive porque -como él mismo sostiene-no podemos entender nuestro mundo político sin comprender las ideas políticas que lo conforman.

Para nuestro autor, las ideas son importantes y tienen consecuencias; por eso, a pesar de que la Ciencia Política empírica parece a menudo no tener las ideas políticas en tanta consideración, sin ellas no se puede comprender la vida política del presente y del pasado. No se puede separar las ideas políticas de la acción política porque las ideas tienen influencia sobre las acciones. Las ideas, las ideologías, tienen impacto sobre las políticas públicas y sobre el destino de los Estados.

Sin embargo, aunque el profesor Freeden nos recuerda la importancia de las ideas políticas, no comparte la metodología de las viejas historias del pensamiento político que parten de un canon de obras y autores prácticamente inmutable y que son 
poco empíricas y muy abstractas. Él cree que esa vieja Historia de las ideas confunde filosofía política y pensamiento político y que no atiende a los problemas concretos ni al contexto intelectual o político, algo que M. Freeden sí que hará en sus escritos.

En definitiva, si -como dice nuestro profesor-consumimos y producimos ideas e ideologías constantemente, deberemos interesarnos en cómo se forman, cómo interactúan y cuáles son sus significados porque estudiar esas ideologías significa comprender la naturaleza de lo político. Pues bien, a eso es a lo que en gran medida ha dedicado su obra Freeden: al estudio de las ideologías, sobre las que ha escrito varios libros, algunos ya traducidos al español como: Ideología. Una breve introducción (2003), además de haber fundado una revista académica dedicada a las ideologías políticas (Journal of Political Ideologies). Freeden aporta en este y otros libros sobre el asunto una nueva luz en cuanto a la definición, características, funciones y el método para estudiar las ideologías.

En cuanto a su definición, Freeden recuerda que las ideologías son productos sociales que constituyen sistemas de valores, creencias, opiniones e ideas que tratan de influir en la opinión pública compitiendo entre ellas. Es decir, constituyen modelos de pensamiento político; aún más: en realidad, son las formas principales del pensamiento político que dan sentido al mundo de la política.

Respecto a sus características, lo primero que hay que recordar es que éstas no son estáticas. Las ideologías son precarias y volátiles. Fluidas, permeables, porosas, ambiguas, móviles y sujetas a transformación interactuando las unas con las otras. Además, cada ideología tiene unos conceptos centrales, los más importantes (como «la lucha de clases» en Marx, por ejemplo), y otros periféricos o secundarios (como fueron en su momento los derechos de las mujeres), que pueden ir ganando o perdiendo importancia con el tiempo porque se dejen de usar, aparezcan conceptos nuevos o se cojan prestados de otras ideologías.

En relación al método para estudiarlas, nuestro profesor considera que hay una metodología propia para su estudio y que hay que estudiarlas desde varios enfoques complementarios y multidisciplinares, aunque con un énfasis importante en el análisis morfológico, el lenguaje, la semántica moderna (sin caer en los excesos del giro lingüístico) y la historia. Esto es así porque las ideologías, como las lenguas, consisten en ciertos conceptos cuyo significado puede cambiar y evolucionar con el tiempo, como señalamos antes.

Insistimos en que Freeden señala que las ideologías son una forma de discurso y compiten por el control del lenguaje político. Lo que hay es una especie de competencia conceptual en la que cada ideología trata de eliminar y rechazar a las rivales (por ejemplo, el marxismo contra el concepto de propiedad privada del liberalismo), aunque también hay competencia interna entre las ideologías (como en Neoliberalismo dentro del Liberalismo). En última instancia, el éxito político de la ideología depende de su habilidad para imponer la creencia de que sus definiciones conceptuales son las correctas.

Además, no solo deben ser analizadas las relaciones entre los conceptos ideológicos, sino que, a veces, hasta hay que descodificarlos porque puede haber significados ocultos en ellos. No conviene olvidar que las ideologías contienen también factores inconscientes y emocionales, como se advierte fácilmente en la actualidad.

En cuanto a su función, las ideologías constituyen una categoría fundamental para entender la teoría y la práctica política: para orientarse en el mundo político, ya que proporcionan mapas del universo político y social dando sentido al mundo en que 
vivimos. Pues los hechos políticos no hablan por sí solos y es la ideología la que nos dice qué significan esos hechos $y$, además -y esto no es una cosa menor-, son instrumentos para las decisiones colectivas.

En definitiva: a pesar del descrédito que las ideologías han sufrido y sufren a menudo (en gran medida por la influencia del análisis marxista), Freeden cree que son, no solo insustituibles, sino respetables. Pues bien, un ejemplo de esta forma de abordar las ideologías lo constituye su estudio sobre el liberalismo, otras de sus interesantes aportaciones y tema en el que es toda una autoridad. A este respecto señalamos su libro de 1978, no traducido, The New Liberalism: An Ideology of Social Reform y otro de 2015 que se acaba de traducir al español: Liberalismo. Una introducción.

Respecto al primer título, Freeden trata de recuperar un tipo de liberalismo que ha sido poco estudiado y subestimado, desafiando las visiones comúnmente aceptadas del pensamiento liberal de fines del siglo XIX. Lo que él estudia es el advenimiento del Nuevo liberalismo a finales de la era victoriana en Inglaterra, pero estudiando no solo los grandes autores sino también otros intelectuales secundarios que se ocupan de la realidad y de los hechos concretos, y que fueron indispensables para reformular el liberalismo de un modo que acabaría dando paso a la sociedad y al Estado de Bienestar. Freeden demuestra que se trataba de un liberalismo avanzado que no era tan individualista como el clásico, que se preocupaba por la reforma social, la moral y la comunidad y por el papel del Estado, permeando así las visiones socialdemócratas (algo no siempre reconocido).

En Liberalismo. Una introducción, Freeden lleva a cabo una especie de guía intelectual en la que queda clara su compleja historia. Describe su evolución, sus logros y sus fallos y demuestra de nuevo cómo no se trata de una ideología estática, sino que es dinámica y flexible, que se reinventa a sí misma constantemente con diferentes variedades. Por eso, habla de liberalismos en plural, aunque sí haya en él unos fundamentos o principios esenciales que no cambian, y aunque sea también algo más que una ideología: un ethos y hasta una conducta como decía Marañón.

Precisamente, en un momento en el que tan a menudo se habla de la decadencia de la democracia liberal y del surgimiento de regímenes «iliberales», es importante tener claro qué significa ser liberal, máxime cuando tan alegremente se adjudican el término movimientos y partidos que poco o nada tienen que ver con la historia y las características del liberalismo. En ese sentido, este libro, que describe sus principios filosóficos (la defensa de la libertad y del pluralismo, la fe en el progreso y la razón, el individualismo y la sociabilidad natural, los derechos humanos y la limitación del poder) y que, además, aporta una serie de lecturas complementarias para seguir profundizando en el tema, sirve muy mucho para aclarar las cosas.

Asimismo, el libro trata desafíos sumamente actuales a los que el liberalismo bien entendido tendría que dar respuesta sin traicionar esos principios básicos (el nacionalismo, la multiculturalidad, la discriminación positiva, la sentimentalización de la política etc.), aunque conviene alertar al lector que el liberalismo de Freeden no es el de un Hayek o el de otros autores neoliberales, sino que su liberalismo es un liberalismo, digamos, "social», que considera grandes autores liberales a un John Stuart Mill, Thomas Hill Green, Hobhouse o Hobson (protagonistas de su libro El nuevo liberalismo).

Freeden es también consciente de que esta tradición de pensamiento político es profundamente europea y por eso, su último libro editado con el profesor español Javier Fernández Sebastián, en 2019, trata sobre el liberalismo europeo. De hecho, se llama Historia conceptual del liberalismo europeo y en él se aplica ese nuevo espíritu de investigación que es el enfoque propio de la historia de los conceptos (Koselleck), 
histórico y comparado. Lo que quiere decir que en esta historia del liberalismo europeo se va a investigar los significados de los conceptos políticos clave a través del tiempo, reflejando su contexto histórico.

Para terminar, aludiremos a uno de sus libros más originales que no se ha traducido todavía, pero cuyo título en español podría ser: La teoría política del pensamiento político: anatomía de una práctica (The political theory of political thinking, an anatomy of a practice): En este libro de 2013 se parte de la idea de que pensar en la política es también una actividad social; que pensar políticamente es también una acción política y que tiene un carácter ubicuo y cotidiano.

Pero es diferente pensar sobre política que pensar políticamente. Por eso, Freeden quiere investigar qué significa decir que los seres humanos piensan políticamente. Qué es distintivo de ese tipo de pensamiento. Cuáles son los rasgos específicamente políticos del pensar políticamente, su lógica y las metodologías específicas.

Y esto es algo que no suelen plantearse los teóricos de la política. De hecho, creo que debe ser el primer estudio sistemático del pensar políticamente como un campo distintivo: lo político como un modo de pensar. De este modo, se cubre una laguna y se amplía el margen de estudio de nuestra disciplina.

Querría insistir en que vemos de nuevo aquí ese deseo de repensar la conexión estrecha de la teoría política con la política práctica. Por eso, en este libro se estudian y examinan modelos reales, pasados o actuales, de cómo la gente piensa políticamente (básicamente sobre cómo vivir una vida colectiva) ${ }^{1}$.

Asimismo, se señalan las nuevas formas de pensar hoy políticamente, llegando a la conclusión de que no estamos en absoluto en la era del Fin de las ideologías sino, al contrario, en otra de cierta creatividad ideológica. No sólo no han desaparecido las ideologías convencionales, sino que éstas se mezclan con otras más fragmentadas, locales o personalizadas que se manifiestan de otras maneras, a veces incluso no verbales.

En definitiva, del mismo modo que la política no puede prescindir de las ideologías ni del pensamiento político, nosotros no podemos prescindir de la obra del profesor Freeden si queremos comprender este mundo político tan complejo e inquietante (y tan poco liberal) que nos ha tocado vivir.

\footnotetext{
1 El rol de tomar decisiones últimas y regular los asuntos sociales; hacer un ranking de las prioridades colectivas; movilizar el apoyo de grupos; conceptualizar tanto el orden social y la estabilidad como el desorden y la inestabilidad; construir planes para la sociedad y su futuro, y el poder del lenguaje, la retórica, razón y emoción.
} 